\title{
A Single Channel IGBT Gate Drivers for Medium Voltage Converters
}

\author{
Sokchea Am*", Phok Chrin, Bunthern Kim, Lim Phing \\ Department of Electrical and Energy Engineering, Institute of Technology of Cambodia, Phnom Penh, Cambodia \\ Email address: \\ sokchea_am@itc.edu.kh(S.Am) \\ ${ }^{*}$ Corresponding author \\ To cite this article: \\ Sokchea Am, Phok Chrin, Bunthern Kim. A Single Channel IGBT Gate Drivers for Medium Voltage Converters. Journal of Electrical and \\ Electronic Engineering. Vol. 9, No. 1, 2021, pp. 16-25. doi: 10.11648/j.jeee.20210901.13
}

Received: February 5, 2021; Accepted: February 14, 2021; Published: February 26, 2021

\begin{abstract}
This article treats the gate driver system for IGBT modules in Medium-Voltage (MV) applications. The study focuses principally on two functions of an IGBT gate driver: an impulse signal transmission and a power transmission. For each function, the suitable topology is proposed. Then, for safety and device's protection reason, all gate driver functions must sustain the high and very high galvanic insulation voltage capabilities. For low-cost design, the insulation system can be achieved with the help of the insulating material in a pot core planar transformer. Therefore, for each function, the optimized design of a pot-core transformer and its associated electronics components is performed with the help of a virtual prototyping tool (a genetic algorithm: GA code in MATLAB ${ }^{\mathrm{TM}}$ ). The first section focuses on optimization design of a selected topology for an impulse signal transmission function. A bi-objective (maximize the output voltage $\mathrm{v}_{\text {out }}$ and minimize the input current $\mathrm{i}_{\text {mos }}$ ) problem of this function that leads to a Pareto front is presented. Several Pareto fronts' results are obtained assuming different insulation layers thickness. The second part focuses on optimization design of a selected topology for a power transmission function. Maximize the converter efficiency $\left(\eta_{\text {con }}\right)$ and minimize the output power $\left(\mathrm{P}_{\text {out }}\right)$ are considered as a bi-objective. Thus, numerous Pareto fronts' results are achieved for a few different insulation thicknesses. Finally, the prototype of a single channel IGBT gate driver is invented to validate the proposed design.
\end{abstract}

Keywords: IGBT Gate Driver, Medium-Voltage Converter, Insulated Transformer, Dielectric Material

\section{Introduction}

Nowadays, the power converter for MV application is mostly used in electric ship, railway electrification, electrical power distribution [1-8]. According to works of literature, numerous modular voltage source converters (VSC) are proposed such as: Multilevel Converter [9], Neutral Point Clamp [10], Flying Capacitors [11], Cascaded Half-Bridge [12], and series connection of IGBT modules [13]. Amongst them, the modular multilevel converter is technically recommended as shown in Figure 1a.

For safety and protection purposes, IGBT gate drivers for IGBT modules in the MV-MMC converter must support the insulation voltage which equals input $D C$ voltage $V_{i n, D C}$ (can reach few of $10 \mathrm{kV}$ as mentioned in Figure $1 \mathrm{~b}$ and [4]). Figure 1c illustrates the main four functions of the IGBT gate driver system [5-8]. In this research paper, the authors address the optimization design of the impulse signal transmission function and the power supply function. The insulation technology is done through the air-gap of the pot core planar transformer (cf. Figure 1d) [22]. With the air gap thickness of $0.5 \mathrm{~mm}$ with a dielectric polyetherimide, the few of $10 \mathrm{kV}$ of insulation voltage level is achieved $[14,15]$.

The optimization methodology for these functions: geometric of transformer is performed with finite element

$\left(\mathrm{FEMM}^{\mathrm{TM}}\right)$ software and transient simulation is done by the simulator $\left(\right.$ LTSpice $\left.{ }^{\mathrm{TM}}\right)$. Hence, the optimization results under Pareto fronts are obtained by the help of a genetic algorithm (GA) coded in MATLAB ${ }^{\mathrm{TM}}$ script which can run FEMM $^{\mathrm{TM}}$ and LTSpice ${ }^{\mathrm{TM}}$ software.

The structure of this paper is divided into three sections: Section 2 presents the optimization for these two functions. Section 3 and Section 4 illustrate the validation results and the conclusions/perspectives, respectively. 


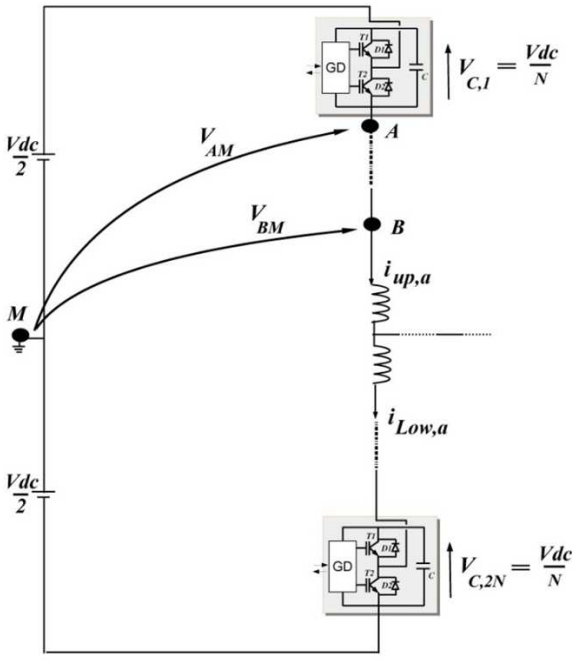

(a)

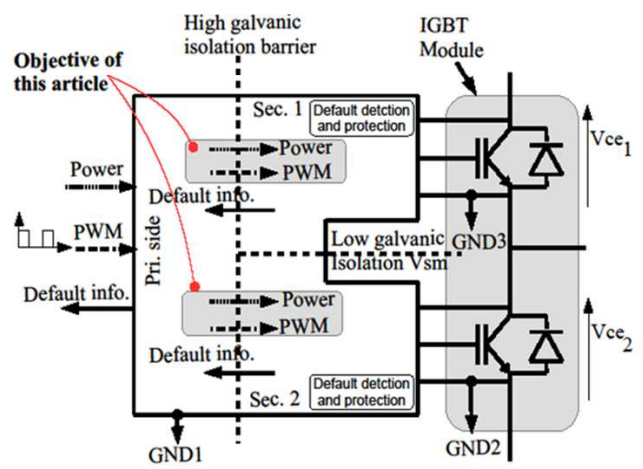

(c)

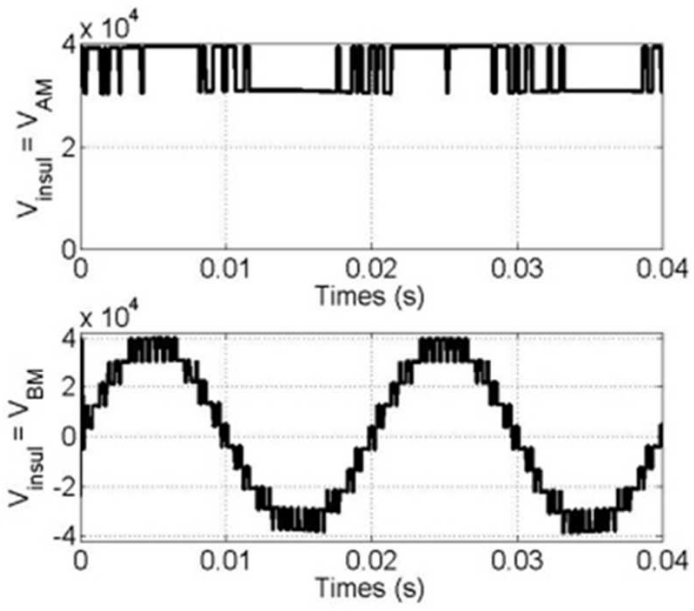

(b)

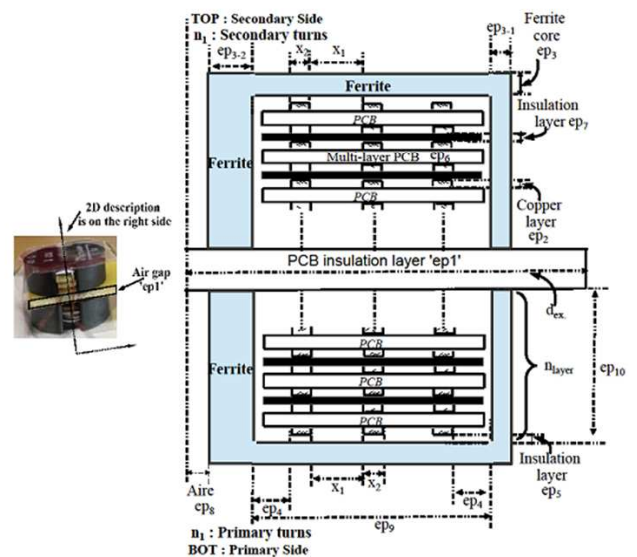

(d)

Figure 1. (a) MV-MMC converter with SMS, (b) determination of insulation voltage level for MV-MMC, (c) IGBT gate driver's functions and objective of this article, (d) geometric of transformer design.

\section{Design for a Single Channel IGBT Gate Driver}

\subsection{Impulse Signal Transmission Function}

Figure 2a presents a proposed circuit for an impulse signal transmission function. According to this figure, a series resonant $\left(\mathrm{C}_{1}, \mathrm{~L}_{\mathrm{p}}, \mathrm{R}_{\mathrm{p}}, \mathrm{N}-\mathrm{MOSFET}\right)$ and a parallel resonant $\left(\mathrm{L}_{\mathrm{s}}\right.$, $\mathrm{R}_{\mathrm{s}}, \mathrm{C}_{2}$ ) are proposed to form an impulse transmission circuit that is generated by N-MOSFET. Moreover, for discharging the energy in $C_{1}, R_{1}=10 \mathrm{k} \Omega$ is required and is located in parallel to this capacitor. The transformer air gap thickness $\left(\mathrm{ep}_{1}\right)$ and its polyetherimide dielectric are used to determine the galvanic insulation voltage level. According to Am et al. [7], $\mathrm{ep}_{1}=\{0.5 \mathrm{~mm}-3 \mathrm{~mm}\}$ can achieved the insulation voltage level more than $10 \mathrm{kV}$.

Maximize the output voltage $\left(\mathrm{v}_{\text {out }}\right)$ and minimize the input current $\left(i_{\text {mos }}\right)$ are set as a bi-objective optimization problem. This current must be minimized for reducing the power consumption in the system. To achieve these bi-objectives, the optimization variables are: $\mathrm{C}_{1}, \mathrm{C}_{2}, \mathrm{R}_{\text {out }}$ (electrical) and $\mathrm{n}_{1}$, $\mathrm{x}_{1}, \mathrm{n}_{\text {layer }}$ (geometrical of the transformer). Then, with the help of the effective virtual prototyping tool (genetic algorithm: GA code) [19-20], the optimization results under the Pareto front forms are obtained.

Optimization variables for an impulse signal transmission function: The optimization variables are abstracted in vector $X: X_{P W M}=\left(n_{1}, x_{1}, n_{\text {layer }}, C_{1}, C_{2}, R_{\text {out }}\right)^{t}$. As presented in Figure $1 \mathrm{~d}, \mathrm{x}_{2}$ is an internal geometrical variable and is expressed in equation (1) as a function of other geometrical variables and parameters. The geometrical parameters are constants and are summarized in Table 1.

$$
x_{2}=\frac{\mathrm{ep}_{9}-2 \mathrm{ep}_{4}-\left(n_{1}-1\right) \mathrm{x}_{1}}{\mathrm{n}_{1}}
$$

Optimization flowchart and constraints for an impulse signal transmission function: Figure $2 \mathrm{~b}$ details the optimization procedure for this proposed design. As presented previously, $v_{\text {out }}$ (to be maximized) and $i_{\text {mos }}$ (to be minimized) are determined as a bi-objective function. And this optimization design process must satisfy the optimization constraints listed in Table 1. 


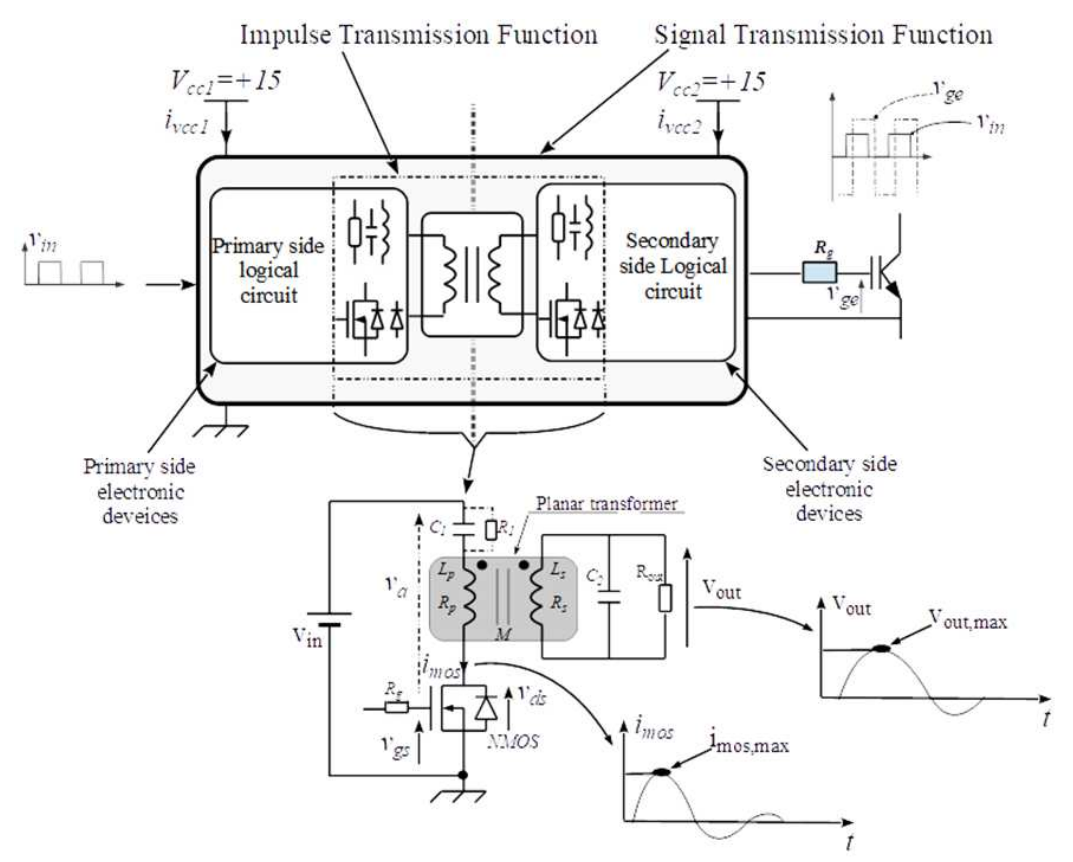

(a)

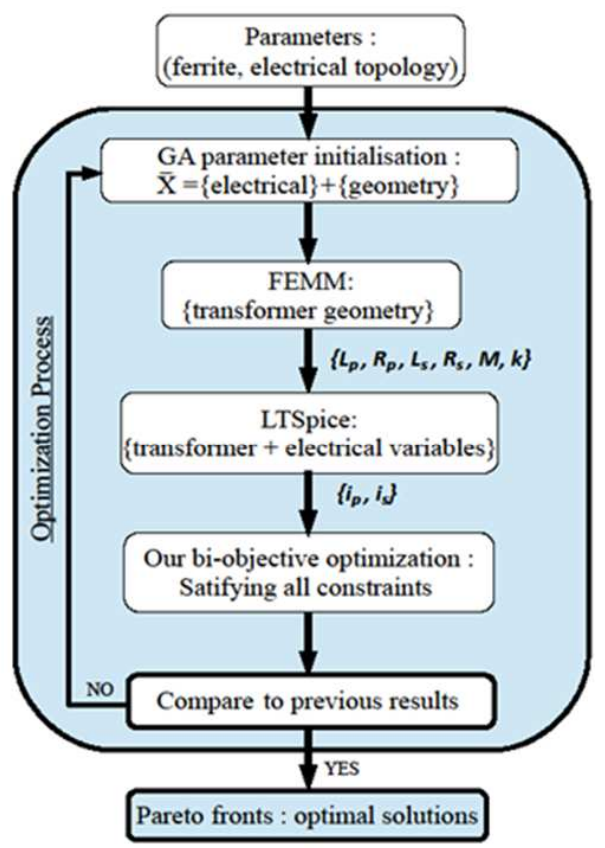

(b)

Figure 2. (a) An impulse signal transmission function, (b) optimization flowchart for this function.

Table 1. Constant parameters and constraints for a transformer.

\begin{tabular}{|c|c|}
\hline Parameters & Values \\
\hline $\mathrm{ep}_{1}$ : air gap & $\{0.5 \mathrm{~mm}$ to $3 \mathrm{~mm}\}$ \\
\hline $\mathrm{ep}_{2}$ : the thickness of the copper & $\{70 \mu \mathrm{m}, 105 \mu \mathrm{m}\}$ \\
\hline $\begin{array}{l}\left\{\mathrm{ep}_{3}, \mathrm{ep}_{3 \_1}, \mathrm{ep}_{32}, \mathrm{ep}_{8}, \mathrm{ep}_{9}, \mathrm{ep}_{10}\right\}: \text { pot core } \\
\text { dimension [21] }\end{array}$ & -- \\
\hline $\mathrm{ep}_{4}$ : reserve length & $0.2 \mathrm{~mm}$ \\
\hline $\mathrm{ep}_{6}$ : PCB layers & $0.4 \mathrm{~mm}$ \\
\hline $\mathrm{ep}_{7}$ : insulation between layers & $18 \mu \mathrm{m}$ \\
\hline $\mathrm{ep}_{5}=\mathrm{ep}_{10}+\mathrm{ep}_{7}-\mathrm{n}_{\text {layer }}\left(e \mathrm{p}_{6}+\mathrm{ep}_{7}+2 \mathrm{ep}_{2}\right)$ & -- \\
\hline $\mathrm{D}_{\mathrm{F}}$ : pot core diameter & $\{7 \mathrm{~mm}, 9 \mathrm{~mm}, 14 \mathrm{~mm}\}$ \\
\hline Opt. constraints & Values \\
\hline $\mathrm{n}_{1}, \mathrm{n}_{\text {layer }}$ & $\{1,5\}$ \\
\hline $\mathrm{x}_{1}$ & {$[0.2 \mathrm{~mm}, 0.4 \mathrm{~mm}]$} \\
\hline $\mathrm{C}_{1}$ and $\mathrm{C}_{2}$ & {$[0.1 \mathrm{nF}, 10 \mathrm{nF}]$} \\
\hline $\mathrm{R}_{\text {out }}$ & {$[1 \mathrm{k} \Omega, 30 \mathrm{k} \Omega]$} \\
\hline $\mathrm{ep}_{5}$ & $\leq 0.3 \mathrm{~mm}$ \\
\hline $\mathrm{C}_{\mathrm{ps}}$ & $\leq 10 \mathrm{pF}$ \\
\hline
\end{tabular}

\subsection{Power Supply Function}

As shown in Figure 3a, a DC-DC isolated power supply is required for supplying the necessary power to electronics and logic components at the secondary side of the gate driver system. For ensuring the operation, the insulation of power supply function and signal transmission function must be at the same level. According to Am et al. [7-8], a full-bridge series-series resonant converter is highly recommended in terms of high efficiency (ZVS operation) and high insulation achievements. Figure $3 \mathrm{~b}$ shows the equivalent circuit of a selected DC-DC power supply topology. This converter constructs with: 4 MOSFETs for an active inverter stage from DC input power to AC output (resonant tank), series resonant tanks $\left(\mathrm{C}_{\mathrm{pr}}\right.$ and $\mathrm{C}_{\mathrm{se}}$ in series with a primary and a secondary winding), four diodes for an uncontrolled rectifier stage. Finally, the filter capacitor $C_{\mathrm{f}}$ has placed to smooth-out the final DC output voltage $\left(\mathrm{V}_{\text {out }}\right)$. Moreover, the voltage ratio $\left(\mathrm{G}_{\mathrm{v}}=\mathrm{V}_{\text {out }} / \mathrm{V}_{\text {in }}\right)$ of this DC-DC converter is illustrated in Figure 3c. According to these $G_{v}$ curves with different load levels, the output voltage can be independent of the magnetic coupling of the transformer and the load when $\mathrm{G}_{\mathrm{v}}=1$. According to the demonstration in the article [7-8] and resonant tanks parameters in Table 2, the voltage transfer ratio is derived as presented in equation (4). Based on this equation and Figure $3 c$, the $G_{v}$ can be operated independently of the magnetic coupling $(\mathrm{k})$ and the load $\left(\mathrm{R}_{\mathrm{L}}\right)$ at frequency $f_{V, H}=$ fres $/ \sqrt{(1-k)}$ where the zero voltage switching (ZVS) condition is achieved [16 - 18].

$$
\begin{aligned}
i_{s e} & =\frac{j \omega M V_{\text {in }}}{\left(z_{s e}+R_{L}\right)\left(z_{p r}+Z_{r}\right)} \\
V_{R I} & =R_{L} \frac{j \omega M V_{\text {in }}}{\left(Z_{s e}+R_{L}\right)\left(z_{p r}+Z_{r}\right)} \\
G_{v} & =\frac{V_{\text {out }}}{V_{g}}=\frac{j \omega M}{\frac{z_{p r} Z_{s e}+(\omega M)^{2}}{R_{L}}+Z_{p r}}
\end{aligned}
$$

The output $P_{\text {out }}$ and the converter efficiency $\eta_{\text {con }}$ of this converter are presented in detail by Dijiruc et al. [14]. Thus, maximize the converter efficiency $\eta_{\text {con }}$ and minimize the output power are set as a bi-objective optimization problem.

Optimization variables for a power supply function: the same as a PWM signal transmission function, the variables compose of the electrical variables $\left(\mathrm{C}_{\mathrm{pr}}, \mathrm{C}_{\mathrm{se}}, \mathrm{f}_{\mathrm{p}}, \mathrm{R}_{\mathrm{out}}\right)$ and geometrical variables (cf. Figure $1 \mathrm{~d}: \mathrm{n}_{1}, \mathrm{x}_{1}, \mathrm{n}_{\text {layer }}, \mathrm{ep}_{2}, \mathrm{ep}_{6}$ ). Thus, the vector optimization variables $X$ is $X_{\text {power }}=\left(n_{1}, x_{1}\right.$, $\left.\mathrm{n}_{\text {layer }}, \mathrm{ep}_{2}, \mathrm{ep}_{6}, \mathrm{C}_{\mathrm{pr}}, \mathrm{C}_{\mathrm{se}}, \mathrm{f}_{\mathrm{p}}, \mathrm{R}_{\text {out }}\right)^{\mathrm{t}}$. Moreover, the optimization parameters are mostly the same as a PWM signal design except for the pot core diameter $\mathrm{D}_{\mathrm{F}}$. For a power supply design, these diameter $D_{F}$ are $14 \mathrm{~mm}, 18 \mathrm{~mm}$, and $22 \mathrm{~mm}$. 


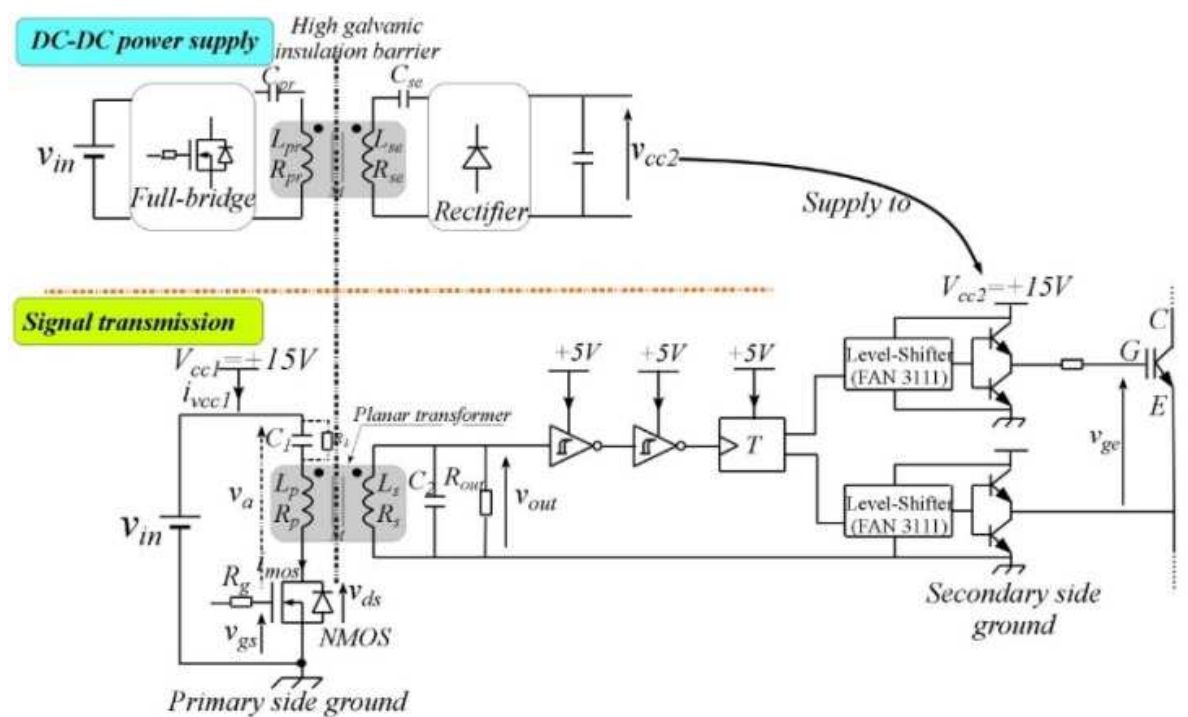

(a)

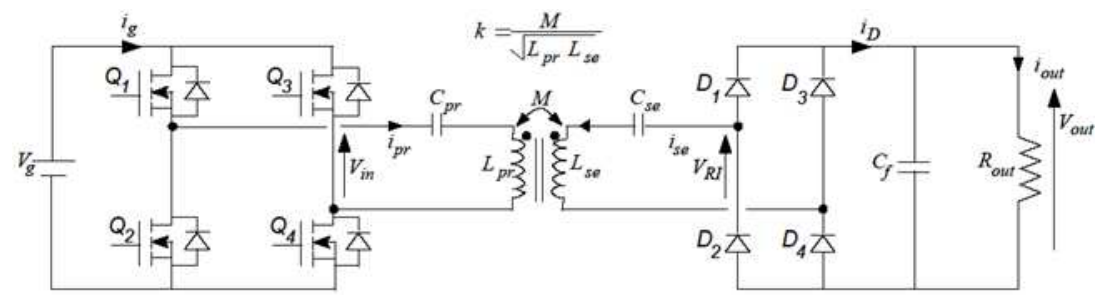

(b)

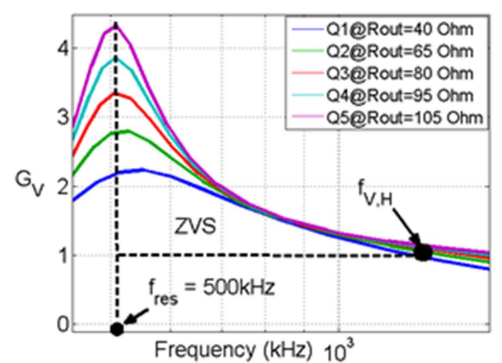

(c)

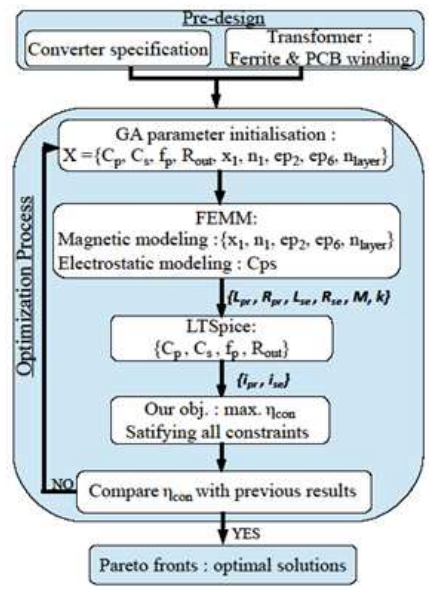

(d)

Figure 3. (a) A complete IGBT gate driver (b) a proposed DC-DC isolated converter for a power supply function, (c) Voltage transfer ration $G_{v}$, and (d) optimization flowchart for this function. 


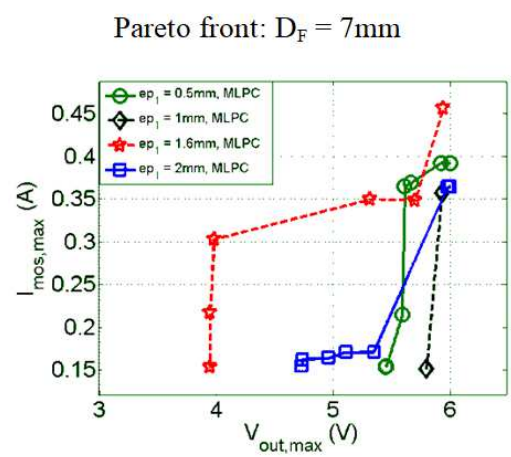

Design target

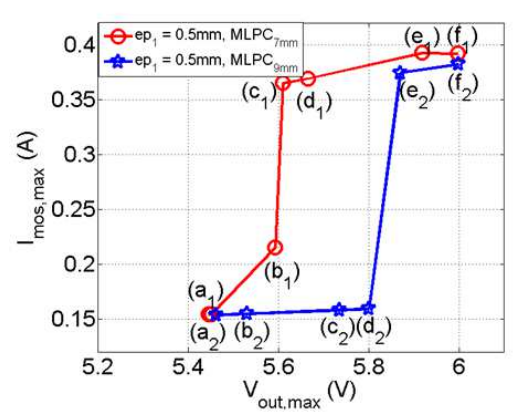

(b)
Pareto front: $\mathrm{D}_{\mathrm{F}}=9 \mathrm{~mm}$

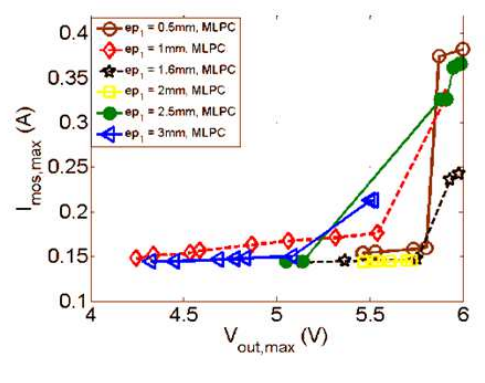

(a)

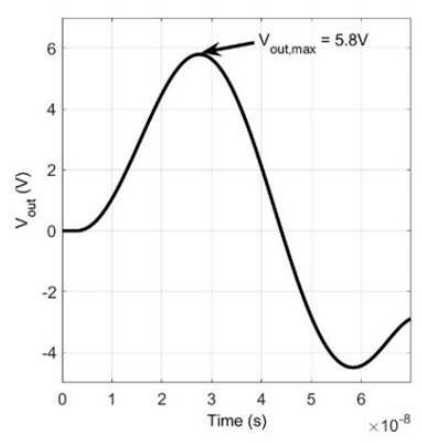

(c)
Pareto front: $\mathrm{DF}=14 \mathrm{~mm}$
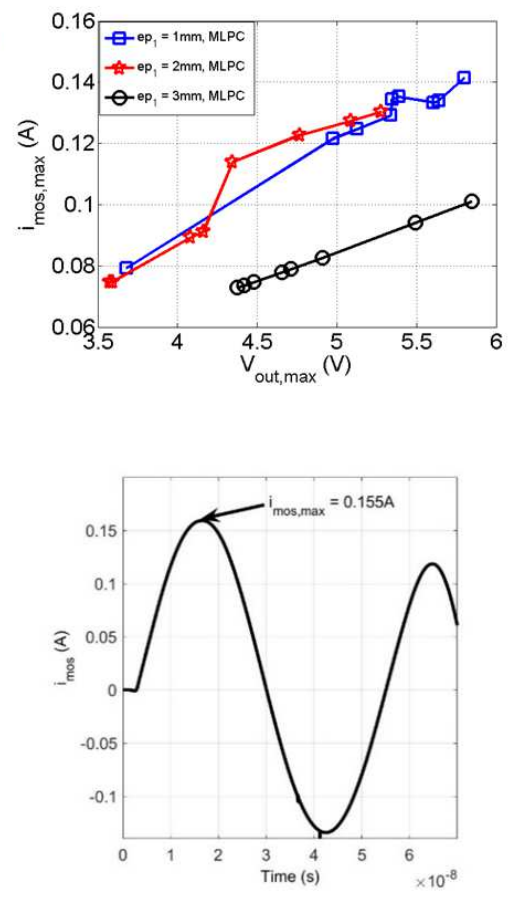

(d)

Figure 4. (a) Pareto front results for different $D_{F}$ and $e_{l}$, (b) design target for the prototype (c)-(d) simulation result of $v_{\text {out }}, i_{\text {mos. }}$, respectively.

Optimization flowchart and constraints for a power supply function: Figure 3d details about the optimization procedure by taking into account all the variables and parameters. But in order to achieve the bi-objective optimization with the feasibility of the physical design, numerous technical constraints must be respected (referred to Table 3 ).

Table 2. Equation of the system (calculations from Figure 3b).

\begin{tabular}{ll}
\hline Definition & Equation \\
\hline Input tank & $V_{i n}=(4 / \pi) V_{g} \sin (\omega t)$ \\
Compensation & $C_{p r}=1 / \omega^{2} L_{p r} ; C_{s e}=1 / \omega^{2} L_{s e}$ \\
Pri. impedance & $Z_{p r}=j \omega \mathrm{L}_{p r}+1 / \mathrm{j} \omega \mathrm{C}_{p r}+R_{p r}$ \\
Sec. impedance & $Z_{s e}=j \omega \mathrm{L}_{s e}+1 / \mathrm{j} \omega \mathrm{C}_{s e}+R_{s e}$ \\
Load & $R_{L}=8 R_{o u t} / \pi^{2}$ \\
Equi. impedance & $Z_{r}=(\omega M)^{2} /\left(\mathrm{Z}_{s e}+\mathrm{R}_{L}\right)$ \\
Input current tank & $i_{p r}=V_{\text {in }} /\left(Z_{p r}+Z_{r}\right)$ \\
Output current tank & $i_{s e}=j \omega M i_{p r} /\left(Z_{s e}+R_{L}\right)$ \\
Output voltage & $V_{R I}=R_{L} i_{s e}=(4 / \pi) V_{\text {out }} \sin (\omega t)$ \\
\hline
\end{tabular}

Table 3. Optimization constraints for a power supply design.

\begin{tabular}{ll}
\hline Description & Constraints \\
\hline $\mathrm{x}_{1}$ & {$[0.2 \mathrm{~mm}-0.5 \mathrm{~mm}]$} \\
$\mathrm{n}_{1}$ & $\{1-5\}$ \\
$\mathrm{n}_{\text {layer }}$ & $\{2-4\}$ \\
$\mathrm{ep}_{2}$ & $\{35 ; 70 ; 105 ; 210 ; 235 ; 435\}[\mu \mathrm{m}]$ \\
$\mathrm{ep}_{6}$ & $\{0.4 ; 0.5 ; 0.8 ; 1.2 ; 1.6\}[\mu \mathrm{m}]$ \\
$\mathrm{C}_{\mathrm{pr}}, \mathrm{C}_{\mathrm{se}}$ & {$[1 \mathrm{nF}-100 \mathrm{nF}]$} \\
$\mathrm{f}_{\mathrm{p}}$ & {$[150 \mathrm{kHz}-1 \mathrm{MHz}]$,} \\
$\mathrm{R}_{\text {out }}$ & {$[10 \Omega-100 \Omega]$,} \\
$\mathrm{V}_{\text {out }}$ & {$\left[\mathrm{V}_{\mathrm{g}}-20 \mathrm{~V}\right]$} \\
$\mathrm{i}_{\text {out }}$ & $\leq 0.5 \mathrm{~A}$ \\
$\mathrm{~B}_{\text {max }}$ & $\leq \mathrm{Bsat}$ \\
$\mathrm{ep}_{5}$ & $\leq 0.5 \mathrm{~mm}$ \\
$\mathrm{C}_{\mathrm{ps}}$ & $\leq 10 \mathrm{pF}$ \\
\hline
\end{tabular}

\section{Simulation and Validation Results}

\subsection{Simulation Results}

A signal transmission function: the optimization results under the Pareto fronts, for $\mathrm{D}_{\mathrm{F}}=\{7 \mathrm{~mm}, 9 \mathrm{~mm}$, and $14 \mathrm{~mm}\}$ and $\mathrm{ep}_{1}=\{05 \mathrm{~mm}$ to $3 \mathrm{~mm}\}$, are shown in Figure $4 \mathrm{a}$. As previously mentioned, an $\mathrm{ep}_{1}=0.5 \mathrm{~mm}$ associated with a polyetherimide material is recommended for the $40 \mathrm{kV} \mathrm{MV}$ MMC application. Thus, with this insulation level, one Pareto front from $\mathrm{D}_{\mathrm{F}}=7 \mathrm{~mm}$ and one Pareto front from $\mathrm{D}_{\mathrm{F}}=$ $9 \mathrm{~mm}$ are considered for the design target as presented in Figure $4 \mathrm{~b}$. Amongst these possible solutions, the solution $\mathrm{d}_{2}$ is selected because of its low power consumption and acceptable voltage information. Table 4 summarized all the numerical values of this solution. Figure $4 \mathrm{c}$ and Figure $4 \mathrm{~d}$ illustrates the output voltage $\mathrm{v}_{\text {out }}$ and a primary side current $\mathrm{i}_{\text {mos. }}$. According to the rate of this current, the proposed PWM signal transmission technology consumes much energy less than the result in the article [5].

A power transmission function: The Pareto fronts ( con versus $\left.\mathrm{P}_{\text {out }}\right)$ for ferrite diameter $\mathrm{D}_{\mathrm{F}}=\{14 \mathrm{~mm}, 18 \mathrm{~mm}, 22 \mathrm{~mm}\}$ and $\mathrm{ep}_{1}=\{0.5 \mathrm{~mm}-3 \mathrm{~mm}\}$ are shown in Figure 5a-c. According to these results, the solution from $\mathrm{D}_{\mathrm{F}}=14 \mathrm{~mm}$ is dominant in terms of the highest efficiency. For the same insulation as an impulse signal transfer, the solution from $\mathrm{ep}_{1}=0.5 \mathrm{~mm}$ is considered. So, the solution (a) is selected for prototype work because of its output power of $2 \mathrm{~W}$ is achieved (cf. Figure $4 \mathrm{~d}$ ). This solution (a) is summarized in Table 4. 


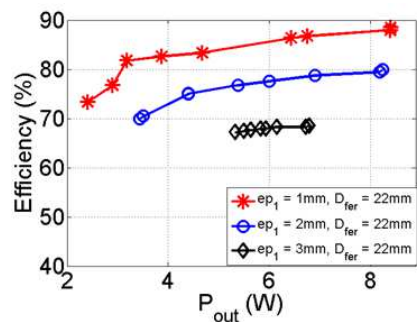

(a)

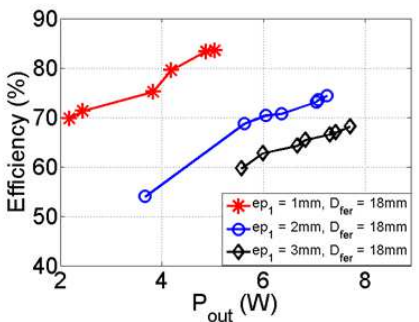

(b)

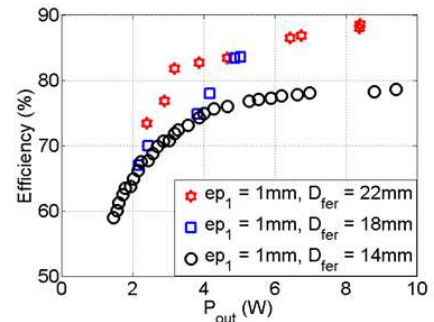

(c)

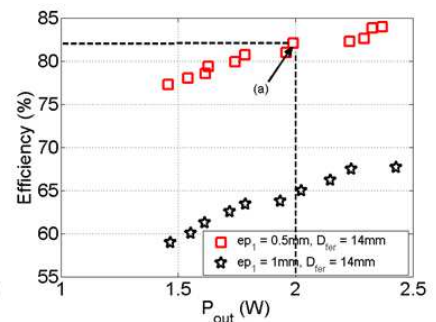

(d)

Figure 5. Pareto front results of a power supply function for different $D_{F}$ : (a) $22 \mathrm{~mm}$, (b) $18 \mathrm{~mm}$, (c) $14 \mathrm{~mm}$, and (d) the optimization design target for prototype.

Table 4. Numerical solutions: solution (d $\left.d_{2}\right)$ for a PWM signal transmission function and solution (a) for a power supply function.

\begin{tabular}{ll}
\hline Optimization results & Solution $\left(\mathbf{d}_{2}\right)$ \\
\hline $\mathrm{V}_{\text {out }} / \mathrm{i}_{\text {mos }}$ & $5.8 \mathrm{~V} / 0.15 \mathrm{~A}($ see Figure $4 \mathrm{c})$ \\
$\mathrm{ep}_{1} / \mathrm{D}_{\mathrm{F}}$ & $0.5 \mathrm{~mm} / 9 \mathrm{~mm}$ \\
$\mathrm{~L}_{\mathrm{p}} / \mathrm{R}_{\mathrm{p}}$ & $2.03 \mu \mathrm{H} / 0.26 \Omega$ \\
$\mathrm{L}_{\mathrm{s}} / \mathrm{R}_{\mathrm{s}}$ & $2.03 \mu \mathrm{H} / 0.26 \Omega$ \\
$\mathrm{M} / \mathrm{k}$ & $1.57 \mu \mathrm{H} / 0.776$ \\
$\mathrm{R}_{\text {out }} / \mathrm{R}_{1}$ & $30 \mathrm{k} \Omega / 10 \mathrm{k} \Omega$ \\
$\mathrm{x}_{1} / \mathrm{n}_{1} / \mathrm{n}_{\text {layer }}$ & $0.32 \mathrm{~mm} / 2$ turns $/ 3$ layers \\
Optimization results & Solution $(\mathrm{a})$ \\
$\eta_{\text {con }} / \mathrm{P}_{\text {out }}$ & $82 \% / 2 \mathrm{~W}$ \\
$\mathrm{~V}_{\text {out }} / \mathrm{I}_{\text {out }}$ & $13.3 \mathrm{~V} / 0.16 \mathrm{~A}$ \\
$\mathrm{ep} / \mathrm{D} / \mathrm{D}_{\mathrm{F}}$ & $0.5 \mathrm{~mm} / 14 \mathrm{~mm}$ \\
$\mathrm{C}_{1} / \mathrm{C}_{2}$ & $68 \mathrm{nF} / 68 \mathrm{nF}$ \\
$\mathrm{L}_{\mathrm{pr}} / \mathrm{R}_{\mathrm{pr}}$ & $17.24 \mu \mathrm{H} / 0.46 \Omega$ \\
$\mathrm{L}_{\mathrm{se}} / \mathrm{R}_{\text {se }}$ & $17.24 \mu \mathrm{H} / 0.46 \Omega$ \\
$\mathrm{M} / \mathrm{k}$ & $10.49 \mu \mathrm{H} / 0.78$ \\
$\mathrm{R}_{\text {out }} / \mathrm{R}_{1}$ & $30 \mathrm{k} \Omega / 10 \mathrm{k} \Omega$ \\
$\mathrm{C}_{\mathrm{ps}}(\mathrm{capacitor}$ parasitic $)$ & $6.67 \mathrm{pF}$ \\
$\mathrm{R}_{\text {out }} / \mathrm{f}_{\mathrm{p}}$ & $76.9 \Omega / 266 \mathrm{kHz}$ \\
$\mathrm{x}_{1} / \mathrm{x}_{2}$ & $0.25 \mathrm{~mm} / 0.87 \mathrm{~mm}$ \\
$\mathrm{n}_{1} / \mathrm{n}_{\text {layer }}$ & $2 \mathrm{turns} / 4$ layers \\
$\mathrm{ep}$ & $105 \mu \mathrm{m} / 0.4 \mathrm{~mm}$ \\
\hline
\end{tabular}

\subsection{Comparison Results}

Figure 6a shows the prototype of a single channel IGBT gate driver. The power supply locates at the lower side. The main components for this function are 2 full-bridge MOSFETs (IRL6372PbF) are controlled by LM5046 controller, 4 diodes (MBRA340T3), a pot core transformer $\left(D_{F}=14 \mathrm{~mm}\right)$, and 2 capacitors. The upper side of Figure $6 \mathrm{a}$ illustrates the prototype of a PWM signal transfer. The main components for this function are N-MOSFET (ZXMN3A01F) is controlled by 74LS32, 2 capacitors, a pot core transformer $\left(\mathrm{D}_{\mathrm{F}}=9 \mathrm{~mm}\right)$ and output resistor. Figure $6 \mathrm{~b}$ presents the sample of the prototype of an optimal transformer. Then, the experimental test-bench is resumed in Figure 6c.

Validation results for a power supply function: According to the voltage transfer ratio $G_{v}$ (cf. Figure 7a), in order to achieve ZVS condition and obtain $\mathrm{V}_{\text {out }} \leq 20 \mathrm{~V}$, the operating frequency must stay between $200 \mathrm{kHz}$ and $350 \mathrm{kHz}$. The comparison results for the selected solution (a) are illustrated in Figure $7 \mathrm{~b}$. The small error between these two cases surely comes from little error values of each component. Figure $7 \mathrm{c}$ shows the comparison results for frequency varies from $200 \mathrm{kHz}$ to $350 \mathrm{kHz}$. Then, another comparison result for load varies $\left(\mathrm{R}_{\mathrm{L}}=[39 \Omega\right.$ to $82 \Omega]$ ) are shown in Figure $7 \mathrm{~d}$. Based on these, the output voltage from $12.5 \mathrm{~V}$ to $13 \mathrm{~V}$ and output power from $2 \mathrm{~W}$ to $4 \mathrm{~W}$ are achieved. Then, the efficiency higher than $74 \%$ is recorded.

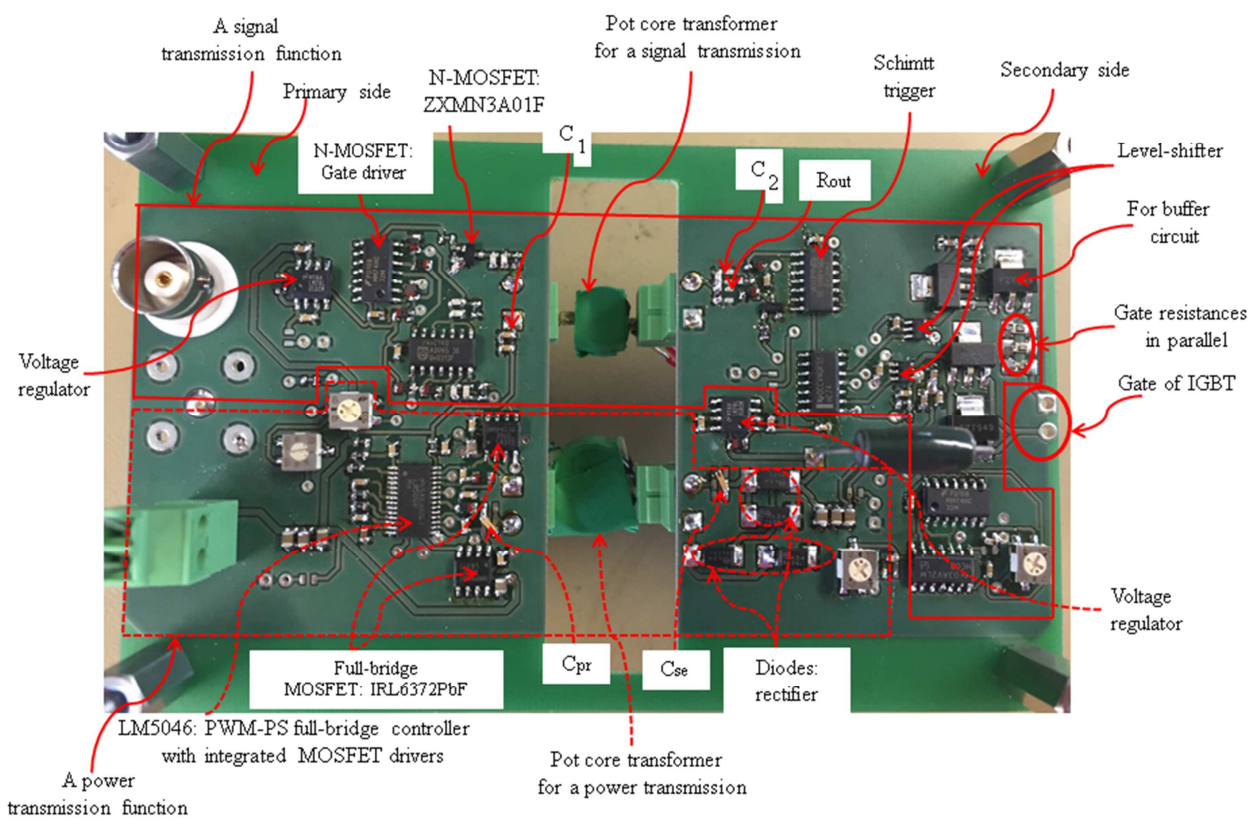

(a) 

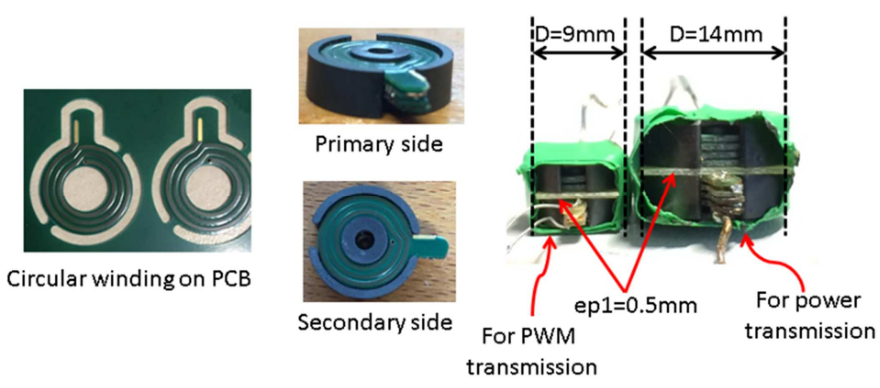

(b)

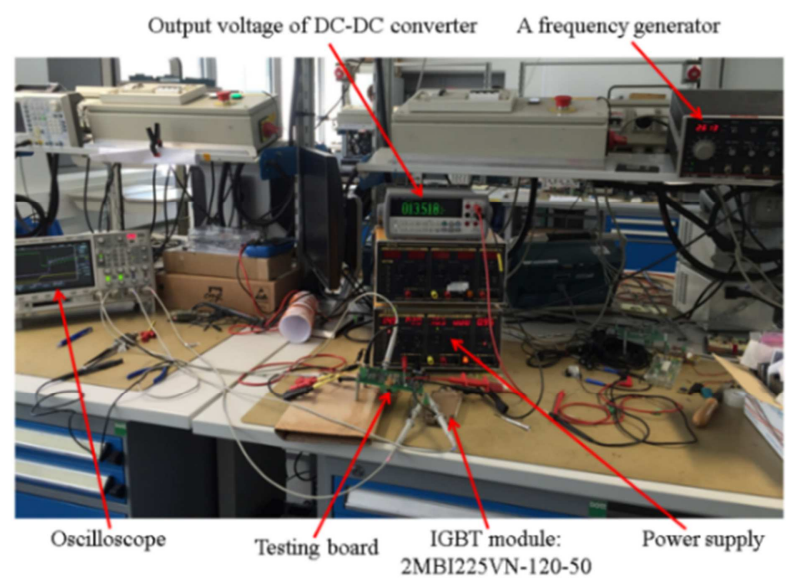

(c)

Figure 6. (a) A prototype of a single channel IGBT gate driver, (b) optimal transformer set-up, (c) Experiment test-bench for the prototype.

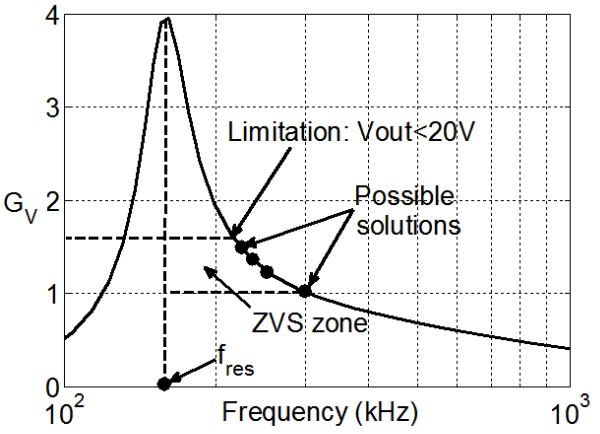

(a)

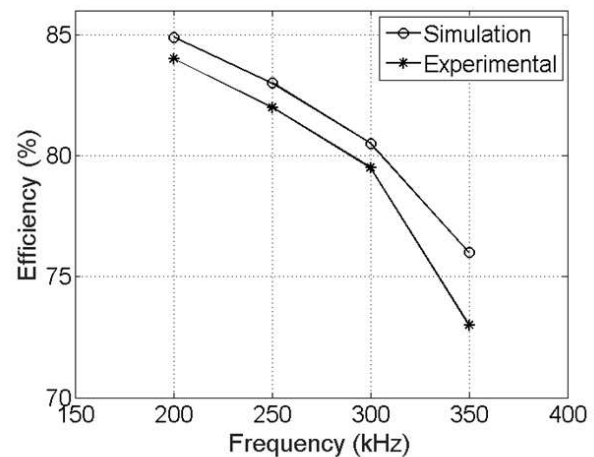

(c)

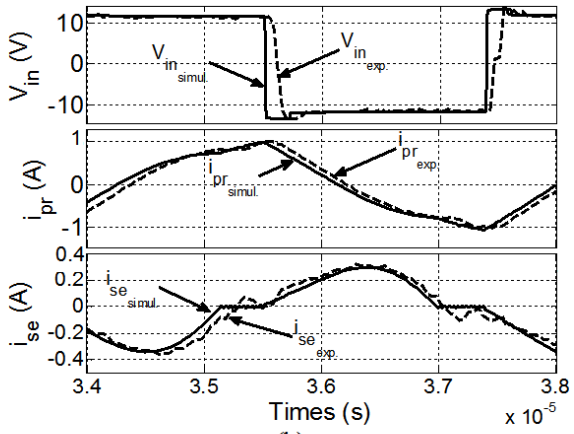

(b)

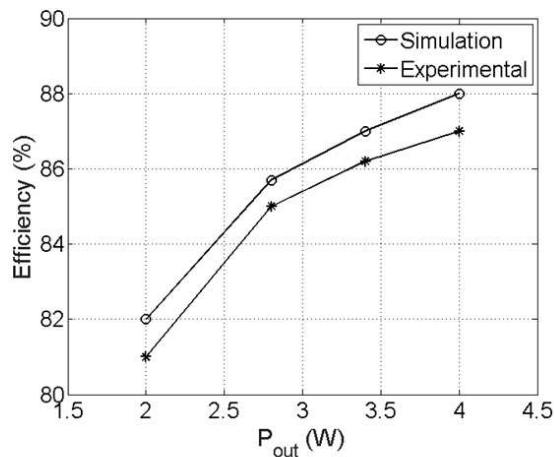

(d)

Figure 7. (a) Voltage transfer ratio: $G_{v}$, (b) validation results for $i_{p r}, i_{s e}, v_{i n}$ of the resonant tanks of solution (a), (c)-(d) converter efficiency for frequency and load varies, respectively.

Validation results for a PWM signal transmission function: As discussed in the previous section, the optimal solution $\left(\mathrm{d}_{2}\right.$ : $\mathrm{D}_{\mathrm{F}}=9 \mathrm{~mm}$ and $\mathrm{ep}_{1}=0.5 \mathrm{~mm}$ ) of a PWM signal transmission function is selected for practical works. Figure $8 \mathrm{~b}$ illustrates the experimental results of the voltages $\mathrm{V}_{\text {out }}$ (output voltage), $\mathrm{V}_{\mathrm{ds}}$ (drain-source voltage of N-MOSFET) and $\mathrm{V}_{\mathrm{ge}}$ (gate- 
emitter voltage of IGBT). According to these experimental results, the propagation delay is around 70ns the same as mentioned in an article Am et al. [5] but consumes less power compared to that article. The output voltage information $\mathrm{V}_{\text {out }}$ of a proposed circuit is the vital variable for experimental validation for comparing to the simulation result. As shown on the left side in Figure 8c, $\mathrm{V}_{\text {out,max }}$ is $5.7 \mathrm{~V}$ for the practical work result which is about $0.1 \mathrm{~V}$ lower than the simulation result. The difference surely comes from the parasitic elements (passive components) and circuit layout.

Furthermore, on the right side of Figure 8c, the comparison waveforms of $i_{\text {mos }}$ are also provided where the peak is about $1.5 \mathrm{~A}$ (for experimental result) and $1.55 \mathrm{~A}$ (for the simulation one). Then, the gate-emitter voltage $\mathrm{V}_{\text {ge }}(\mathrm{t})=$ $+/-15 \mathrm{~V}$ of the IGBT module is achieved as illustrated in Figure $8 \mathrm{~d}$ for a few electrical periods.

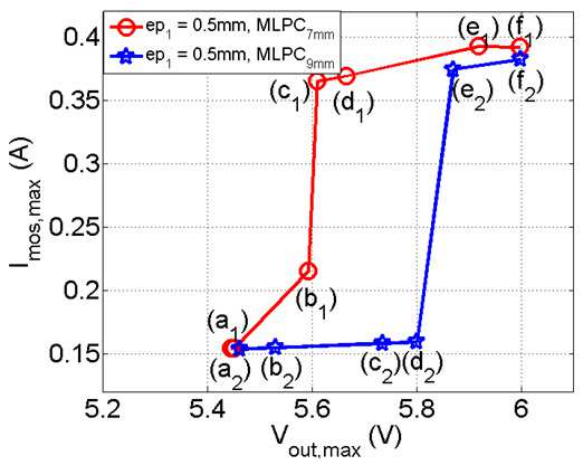

(a)

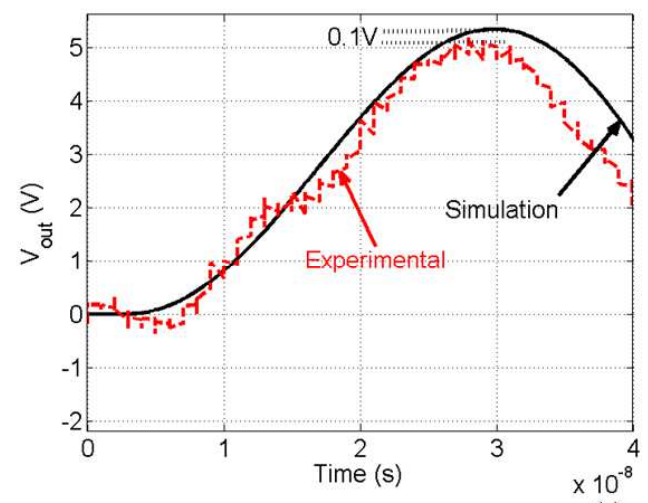

\section{Conclusion}

This research article presents a high insulation voltage single-channel IGBT gate driver: a power supply function and a PWM signal transmission function. Two proposed topologies are described for the application where the insulation voltage of $40 \mathrm{kV}$ is required. This voltage level can be achieved by using $0.5 \mathrm{~mm}$ air-gap with polyetherimide material of pot core transformers.

For the PWM signal transmission function, several optimal Pareto fronts are obtained. Amongst these solutions, the solution $\mathrm{d}_{2}\left(\mathrm{ep}_{1}=0.5 \mathrm{~mm} / \mathrm{D}_{\mathrm{F}}=9 \mathrm{~mm}\right)$ is selected for experimental works. For the power supply function, a fullbridge resonant topology is chosen. Then, numerous optimization results under Pareto front forms are obtained for different insulation voltage levels. Optimal solution a $\left(\mathrm{ep}_{1}=\right.$ $0.5 \mathrm{~mm} / \mathrm{D}_{\mathrm{F}}=14 \mathrm{~mm}$ ) is selected for practical works.

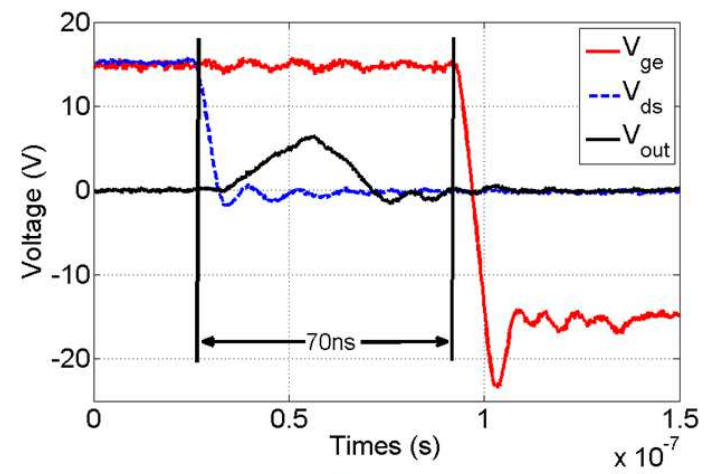

(b)

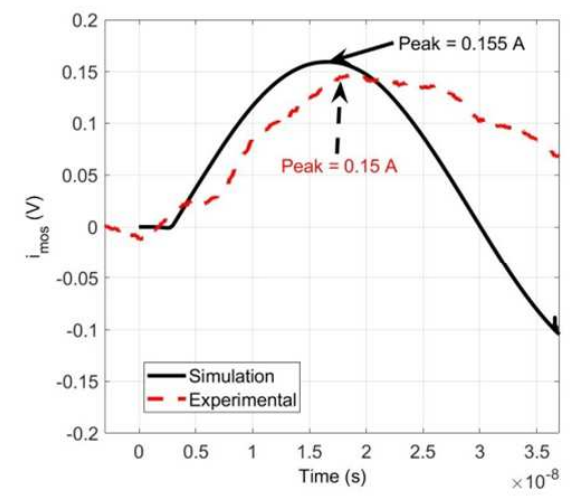

(c)

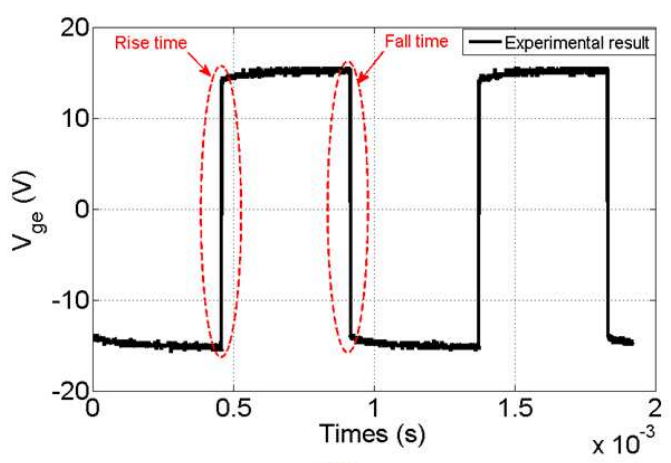

(d)

Figure 8. (a) optimization solution $\left(d_{2}\right)$ of a PWM signal transmission function, (b) waveform of $V_{\text {out }}, V_{d s}$ of MOSFET at primary side and $V_{g e}$ of IGBT for a solution $\left(d_{2}\right)$, (c) The comparison results in the output voltage and a primary side current, (d) $V_{g e}(t)=-1+15 \mathrm{~V}$ of IGBT module. 
For the experimental works, two optimal transformers and experimental boards are set up. Then, the experimental waveforms are measured to compare with the simulation ones. The comparison trends for important variables are shown with a small difference that comes from the parasitic elements and circuit layout.
For the next study, the authors focus on a very high insulated power transmission of gate drivers in a series connection of multiple power devices. The series connection of multiple devices is shown in Figure 9. We will investigate on a power transformer, EMI reducing architecture, minimization of the parasitic capacitor, etc.

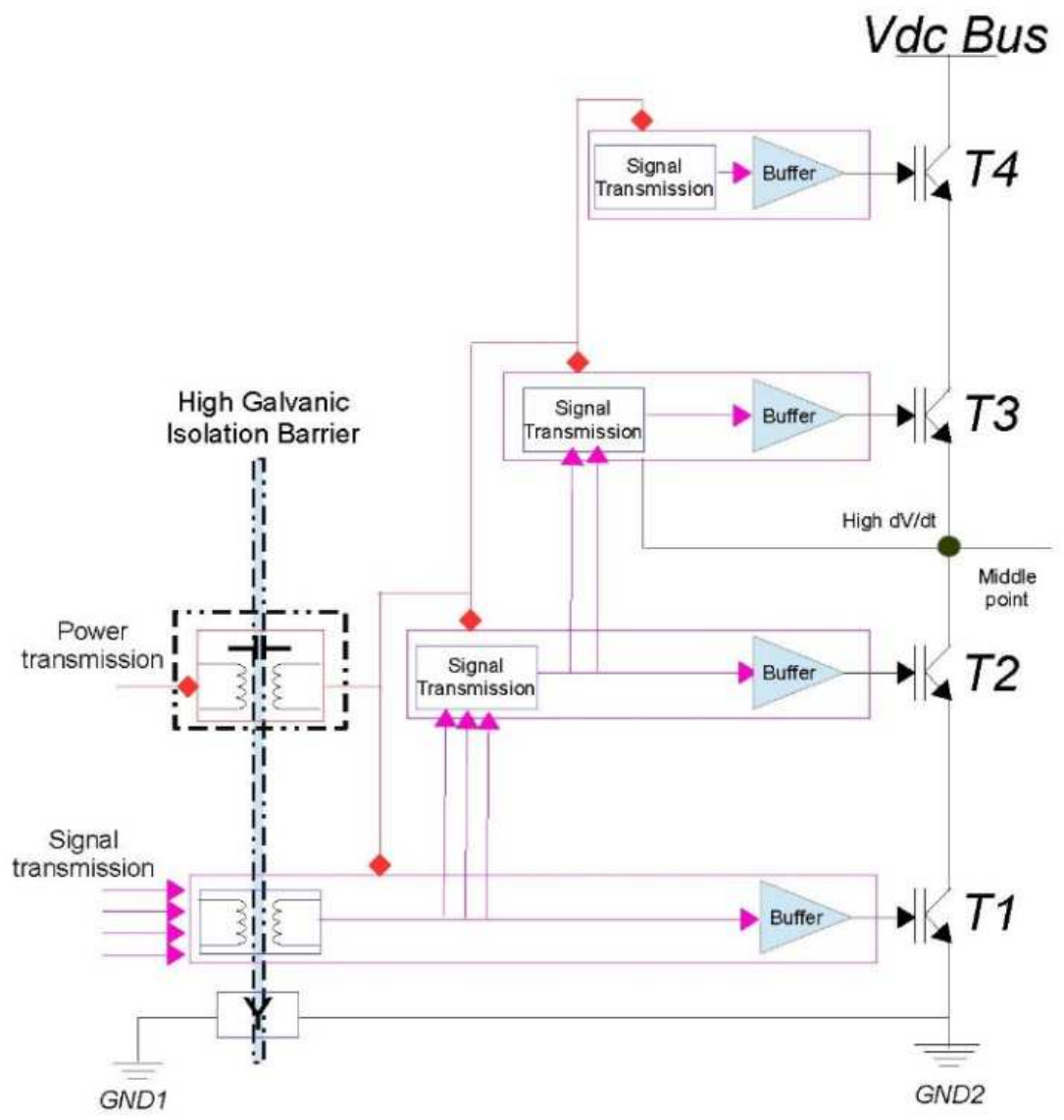

Figure 9. A synopsis of high insulated power transmission for a series connection of power devices.

\section{Acknowledgements}

The authors acknowledge the financial support from " JICA Research Grant for Lab. Based Education - LBE 2020", Japan and the financial support from the "Higher Education Improvement Project - HEIP”, Royal Government of Cambodia (RGC), Cambodia.

\section{References}

[1] F. Wang, Z. Zhang, T. Ericsen, R. Raju, R. Burgos and D. Boroyevich, "Advances in Power Conversion and Drives for Shipboard Systems," in Proceedings of the IEEE, vol. 103, no. 12, pp. 2285-2311, Dec. 2015.

[2] Nounou, K., Benbouzid, M., Marouani, K. et al. Performance comparison of open-circuit fault-tolerant control strategies for multiphase permanent magnet machines for naval applications. Electr Eng 100, 1827-1836 (2018) doi: 10.1007/s00202-0170661-9.

[3] Holtz, J., Krah, J. O. "On-line identification of the resonance conditions in the overhead supply line of electric railways" Archiv f. Elektrotechnik 74, 99-106 (1990) doi: 10.1007/BF01573236.

[4] Am, S.; 'Power modules design and optimization for medium power of MMC inverters. High insulation voltage gate driver system and 3D packaging,' PhD dissertation, G2Elab, 2016, available at https://hal.archives-ouvertes.fr/tel-01534816v1

[5] S. Am, P. Lefranc and D. Frey, "Design methodology for optimising a high insulation voltage insulated gate bipolar transistor gate driver signal transmission function", IET Power Electron., vol. 8, no. 6, pp. 1035-1042, 2015.

[6] P. Lefranc, X. Jannot and P. Dessante, "Optimised design of a transformer and an electronic circuit for IGBT drivers signal impulse transmission function based on a virtual prototyping tool", IET Power Electronics, vol. 6, no. 4, pp. 625-633, April 2013.

[7] S. Am, P. Lefranc, D. Frey and M. Ibrahim, "Design methodology for a high insulation voltage power transmission function for IGBT gate driver," 2016 IEEE Applied Power Electronics Conference and Exposition (APEC), Long Beach, CA, USA, 2016, pp. 2401-2408, doi: 10.1109/APEC.2016.7468202. 
[8] Sockea Am, Pierre Lefranc, David Frey., "A Virtual Prototyping Tool of a Power Transmission Function for IGBT Gate Drivers with High Insulated Voltage Capabilities." CIPS: International Conference on Integrated Power Electronics Systems 2016, Mar 2016, Nuremberg, Germany.

[9] M. Glinka and R. Marquardt, "A new AC/AC multilevel converter family," in IEEE Transactions on Industrial Electronics, vol. 52, no. 3, pp. 662-669, June 2005, doi: 10.1109/TIE.2005.843973.

[10] N. Li, Y. Wang, R. Niu, W. Guo, W. Lei and Z. Wang, "A novel neutral point voltage automatic balancing carrier-based modulation strategy of three-level NPC converter," 2014 International Power Electronics Conference (IPEC-Hiroshima 2014 - ECCE ASIA), Hiroshima, Japan, 2014, pp. 475-479, doi: 10.1109/IPEC.2014.6869626.

[11] V. Dargahi, et al. "Flying Capacitors Reduction in an Improved Double Flying Capacitor Multicell Converter Controlled by a Modified Modulation," in IEEE Transactions on Power Electronics, vol. 27, no. 9, pp. 3875-3887, Sept. 2012, doi: 10.1109/TPEL.2012.2188647.

[12] V. Sonti, et al. "Analysis for the Minimization of Leakage and Common Mode Currents in Cascaded Half-Bridge PV Fed Multilevel Inverter," IEEE JESTPE, vol. 7, no. 4, pp. 24432452, 2019.

[13] V.-S. Nguyen, et al. "Gate driver supply architecture for common mode conducted EMI reduction in series connection of multiple power devices," IEEE TPEL, 2018.

[14] S. Djuric, G. Stojanovic, M. Damnjanovic, M. Radovanovic and E. Laboure, "Design, Modeling, and Analysis of a Compact Planar Transformer," in IEEE Transactions on Magnetics, vol. 48, no. 11, pp. 4135-4138, Nov. 2012, doi: 10.1109/TMAG.2012.2202642.

[15] S. Am, P. Lefranc, D. Frey and R. Hanna, "Design methodology for very high insulation voltage capabilities power transmission function for IGBT gate drivers based on a virtual prototyping tool", IET Power Electronics, vol. 10, no. 5, pp. 545-554, 2017.

[16] B. Sarrazin, R. Hanna, P. Lefranc, S. Am, F. Dumas and J. P. Lavieville, "Insulated power supply for gate drivers up to 40 $\mathrm{kV}$ for medium-voltage direct current applications", IET Power Electronics, vol. 10, no. 15, pp. 2143-2148, 2017.

[17] Chwei-Sen Wang, O. H. Stielau and G. A. Covic, "Design considerations for a contactless electric vehicle battery charger," in IEEE Transactions on Industrial Electronics, vol. 52, no. 5, pp. 1308-1314, Oct. 2005, doi: 10.1109/TIE.2005.855672.

[18] Z. Huang, S. Wong and C. K. Tse, "Design methodology of a series-series inductive power transfer system for electric vehicle battery charger application," 2014 IEEE Energy Conversion Congress and Exposition (ECCE), Pittsburgh, PA, USA, 2014, pp. 1778-1782, doi: 10.1109/ECCE.2014.6953633.

[19] AL-Kandari, A. M., EL-Naggar, K. M. A genetic-based algorithm for optimal estimation of input-output curve parameters of thermal power plants. Electr Eng 89, 585-590 (2007) doi: 10.1007/s00202-006-0047-x.

[20] Chen, G.; et al. "Parameter Optimization of the LC filters Based on Multiple Impact Factors for Cascaded H-bridge Dynamic Voltage Restorers," JPE, 2014.

[21] Liu, S.; et al. "Study on the Parameter Optimization of Softswitching DC/DC Converters with the Response Surface Methodology, a SPICE Model, and a Genetic Algorithm," JPE, 2015.

[22] Magnetics, " Ferrite core Magnetic Catalog: Applications and Material," Magnetics International 13/F 1-3 Chatham Road South Tsim Sha Tsui Kowloon, Hong Kong 2017 (website: www.mag-inc.com). 